\title{
A Prospective Study on Adhesive Intestinal Obstruction in a Tertiary Care Centre, South India
}

\author{
Bhaskar Babu GN *1, Naresh Y ${ }^{2}$, Shivakrishna G ${ }^{3}$.
}

${ }^{* 1}$ Senior Resident, Department of General Surgery, Government M edical College and General Hospital, Anantapuram. Andhra Pradesh, India.

${ }^{2}$ Assistant Professor, Department of Biochemistry, Viswabharathi M edical College, Kurnool. A.P.

${ }^{3}$ Tutor, Department of Biochemistry, Andaman and Nicobar Island Institute of M edical Sciences, Port Blair, India.

\section{ABSTRACT}

Introduction: Bowel obstruction remains one of the most common presentation of acute abdomen encountered by general surgeons in their routine clinical practice. It remains one of the major causes of morbidity and mortality in acute emergencies.

Aim of the study: The present study was focused to prospectively evaluate and analyze the various types of clinical manifestations, etiology, management and outcome among patients diagnosed with acute intestinal obstruction pertained to South Indian population admitted in a tertiary care centre, Andhra Pradesh.

Materials and Methods: The present cross sectional prospective study includes patients diagnosed with acute intestinal obstruction at Department of General Surgery, SVRGGH, Tirupati, Andhra Pradesh, India. A total of 70 were included to evaluate incidence, causes, symptoms and signs at the time of presentation, associated complications, management and mortality of AlO.

Results and Discussion: The mean age at the time of the presentation with AIO was found to be $48 \pm 16$ years. The most common age group diagnosed with AIO was between $31-40$ years (24\%). The male to female ratio observed was 2.2:1. Pain abdomen was the most common symptom in $90 \%$, followed by vomiting ( $80 \%$ ), abdominal distension (65\%), and constipation (52\%). The most common cause of admission was post operative adhesions (48\%) followed by obstructed hernia (20\%). The most common surgical management of adhesions was done by release of adhesions (48\%). Complications noticed during the course of the present study include septicemia $(6 \%)$, wound infection $(3 \%)$, respiratory tract infection $(3 \%)$ and wound dehiscence $(2 \%)$. The results of the present study are in agreement with the earlier studies.

KEY WORDS: Acute abdomen, Acute Intestinal obstruction, Post operative adhesions.

Address for correspondence: Dr. Bhaskar Babu GN, Senior Resident, Department of General Surgery, Government M edical College and General Hospital, Anantapuram. Andhar Pradesh.

E-Mail: gnbkmc1982@gmail.com

\begin{tabular}{|c|ll|}
\hline \multicolumn{3}{|c|}{ Online Access and Article Informtaion } \\
\hline Quick Response code & \multicolumn{2}{|c|}{ International Journal of Integrative Medical Sciences } \\
& \multicolumn{2}{|c|}{ www.imedsciences.com } \\
\cline { 2 - 3 } $\begin{array}{c}\text { Dol: } 10.16965 / \text { ijims.2015.133 } \\
\text { Deceived: 17-10-2015 }\end{array}$ & Reviewed: 18-10-2015 & Accepted: 02-11-2015 \\
\hline Source of Funding: Self & \multicolumn{3}{|c|}{ Conflicts of interest: None } \\
\hline
\end{tabular}

\section{INTRODUCTION}

Bowel obstruction remains one of the most common causes of acute abdomen that lead to significant morbidity and mortality across globally and in India. Clinical presentation of acute intestinal obstruction often poses a sing- nificant challenge to surgeons. Most of the manifestations include atypical and nonspecific features such as mild abdominal discomfort and distension to a state of hypovolemic or septic shock requiring emergency interventions [1]. 
Prior abdominal or pelvic surgery, abdominal wall or groin hernia, Intestinal inflammation, Neoplasms, Prior irradiation and History of foreign body ingestion are the most important risk factors for mechanical small bowel obstruction. Although a wide range of etiological factors are responsible, it is observed that the causes of acute intestinal obstruction are succumbing to vary according to the geographical areas, ethnicity, race and lifestyle changes [2,3]. With improved diagnostic facilities, invention of potent antimicrobials and application of stringent sterilization procedures, it was possible for early diagnosis and management of acute bowel obstruction with observed decreased morbidity and mortality. Instead most of the deaths are observed due to complications associated with inaccurate diagnosis, failure of pre-operative evaluation, post-operative management and associated co morbid illness. Hence, it is the acumen of the surgeons to have deep insight into the acute abdomen to rule out acute intestinal obstruction.

\section{MATERIALS AND METHODS}

Study subjects: It is Cross sectional prospective study performed in between May 2012 to April 2014 and included 70 patients presented to Department of General Surgery, S.V.R.R.G.G. Hospital, Tirupati, Andhra Pradesh, india, with symptoms of acute abdomen and diagnosed as Acute Intestinal Obstruction. Age less than 20 years, hemodynamically unstable, prisoners and mental retarded patients were excluded from the study. A detailed well informed consent was taken from all the subjects included in the present study. The study was approved by institutional ethical committee.

Study methods: Demographic data and time of event leading to obstructive symptoms, clinical history, physical examination and relevant investigations were collected from all the study subjects presented with acute intestinal obstruction as per the prescribed proforma. Operative findings, operative procedures, complications during the admission and subsequent follow-up were all recorded on proforma.

Statistical Analysis: All data were expressed as percentages or frequencies and $M$ ean $\pm \mathrm{SD}$ for categorical and continuous variables respectively. Chi square analysis and independent sample $T$ test was performed among categorical and continuous variables to evaluate the significance of difference among groups. A P value $<0.05$ were considered statistically significant. The statistical analysis was performed using Microsoft Excel Spread sheets and SPSS software 11.5 Version, Chicago, USA.

\section{RESULTS}

The mean age at the time of the presentation was $48 \pm 16$ years. It was observed that most common age group diagnosed with AIO was between $31-40$ years (24\%) followed by $21-30$ (17\%) and 51-60 years (17\%). M ales were higher than females with male to female ratio being 2.2:1.

The most common symptom was pain abdomen observed in $90 \%$ cases, followed by vomiting (80\%), abdominal distension (65\%), constipation $(52 \%)$. Observation of signs in patients suspected of AlO showed previous abdominal surgical scars (48\%), visible peristalsis (30\%), tenderness in $29 \%$ and guarding (22\%) as shown in Figure 1.

Fig. 1: Clinical presentation of patients diagnosed with acute intestinal obstruction.

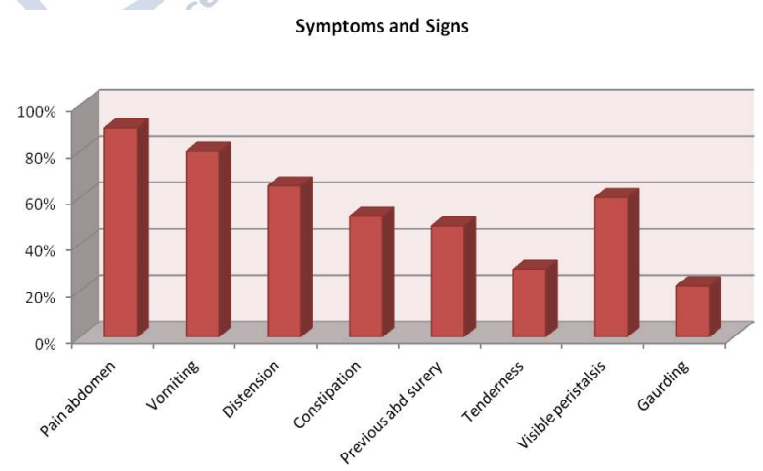

The most common cause of admission with acute intestinal obstruction was post operative adhesions (48\%) followed by obstructed hernia (20\%), tuberculous abdomen (12\%), vovlulus $(10 \%)$, mesenteric ischemia (6\%) and malignancies (4\%). It was observed in the present study that the least number of cases were presented with AIO due to malignancies (4\%) $\mathrm{t}$.

Surgical management of adhesions was done by release of adhesions ( $48 \%$ ), constriction release 
and anatomical repair in obstructed/strangulated hernia (20\%), resection and end to end anastamosis for volvulus (15\%) and Hartman's procedure for malignancies (4\%). Patients diagnosed with AIO secondary to tuberculosis abdomen were managed conservatively with Anti Tuberculosis Treatment (ATT) (12\%) as shown in figure 2.

Fig. 2: M anagement of various causes of acute intestinal obstruction.

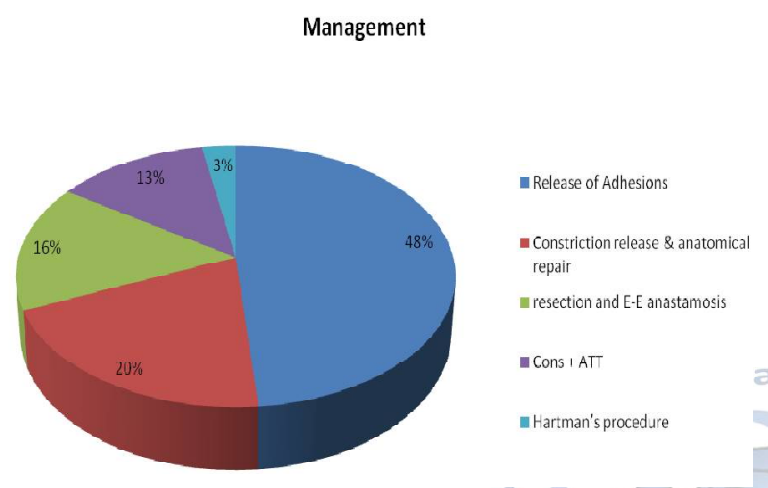

Complications noticed during the course of the present study include septicemia (6\%) followed by minor percentage of wound infection (3\%), respiratory tract infection (3\%) and wound dehiscence (2\%).

\section{DISCUSSION}

Acute intestinal obstruction continues to be the most common diagnosis that needs an emergency medical and surgical intervention. The present study was intended to evaluate the incidence of the types, causes, clinical presentations, management and prognosis among the patients diagnosed with acute intestinal obstruction in south Indian population admitted in a tertiary care hospital.

In the present study, it was observed that pain abdomen was the most common presentation observed in $90 \%$ cases, followed by vomiting (80\%), abdominal distension (65\%), constipation (52\%). Observations of signs in patients suspected of AIO revealed tenderness in 29\% of cases, guarding in $22 \%$, visible peristalsis in $30 \%$ and previous abdominal surgery has been elucidated in $48 \%$ cases. The results of the present study are in agreement with previous studies by Jean Jacques D et al [4], Adhikari S et al [5] and Khan JS et al [6].

In the present study, it was observed that the most common cause of admission with acute intestinal obstruction was post operative adhesions (48\%) with the least number presented with malignancies (4\%). Although the most common cause of AIO was observed to be obstructed/strangulated inguinal hernia, there is change in trend towards post operative adhesions being the most common cause of AIO. The possible explanation for this changing trend might be due to improved diagnosis, early surgical intervention and increased awareness among the patients. The results of the present study are in agreement with the earlier studies by Khan JS et al [6], Menzies D et al [7], and Playforth et al [8].

Among the 70 cases studied under the present study, various modalities of management have been applied depending upon the respective diagnosis. Surgical management of adhesions was done by release of adhesions with constriction release and anatomical repair in patients diagnosed with obstructed/strangulated hernia.

There was observation of decreased incidence of post operative complications in patients managed immediately after confirmation of diagnosis. However, some of the observed complications noticed during the course of the present study include septicemia (6\%) followed by minor percentage of wound infection, respiratory tract infection and wound dehiscence. The increased observation of septicemia as complication in the present study might be contributed due to presence of existing sepsis or with improper preparation of patient before surgery or due to post operative secondary infections. Respiratory tract infection was observed due to presence of Chronic obstructive pulmonary disease as comorbid illness.

It was observed that seven (7) cases died due to advanced age, various complications and comorbid illness. Among these, two (2) cases died due to secondary metastasis of carcinoma and two (2) cases due to mesenteric ischemia. The results of the present study are in accordance with the earlier studies by Khan JS et al. [5], Sinha S et al [9] and Adhikari S et al. [9]. 


\section{CONCLUSIONS}

The present infers that patients diagnosed AIO present most commonly as pain abdomen with post operative adhesions as the most common cause of AIO. Despite the smaller number of complications secondary to septicemia noticed in the present study, prompt diagnosis with optimal surgical interventions might decrease the morbidity and mortality secondary to AIO.

\section{REFERENCES}

[1]. Houghton SG, De la M edina AR, Sarr M G. Chapter 17. Bowel obstruction. In: Maingot's Abdominal operations, M ichael J. Zinner, Stanley W Ashley, eds. $11^{\text {th }}$ edition. .New York: M cGraw-Hill Medical; 2007. pp. 479-505.

[2]. Markogiannakis $\mathrm{H}$ et al. Acute mechanical obstruction: Clinical presentation, aetiology, management and outcome. World J Gastroenterol 2007 Jan;13(3):432-7.

[3]. Ellis H, Moran BJ, Thompson JN, et al. Adhesionrelated hospital readmissions after abdominal and pelvic surgery: a retrospective cohort study. Lancet 1999; 353:1476-80.
[4]. Jean-Jacques Duron, Nathalie Jourdan-Da Silva, Sophie Tezenas du Montcel, Berger A, Muscari F, Hennet $\mathrm{H}$ et al. Adhesive Postoperative Small Bowe Obstruction: Incidence and Risk Factors of Recurrence After Surgical Treatment. Annals of Surgery 2006; 244(5):750-57.

[5]. Adhikari S, Hossein MZ, Das A, M itra N, Ray U. Etiology and outcome of acute intestinal obstruction: A review of 367 patients in Eastern India. The Saudi Journal of Gastroenterology 2010;16(4):285-7.

[6]. Khan JS, Alam J, Hassan H, Iqbal M. Pattern of intestinal obstruction a hospital based study. Pak Armed Forces M ed J 2007;57(4):295-9.

[7]. Menzies D, Parker M, Hoare R, Knight A. Small bowel obstruction due to postoperative adhesions: treatment patterns and associated costs in 110 hospital admissions. Ann R Coll Surg Engl 2001;83:40-6.

[8]. Playforth RH. Mechanical small bowel obstruction and plea for the earlier surgical intervention. Ann Surg 1970;171:783-8.

[9]. Sinha S, Kaushik R, Yadav TD, Sharma R, SAA, Attri AK. Mechanical bowel obstruction. Chandigarh experience. Trop Gastroenterol 2002;23(1):13-5.

How to cite this article:

Bhaskar Babu GN, Naresh Y, Shivakrishna G. A Prospective Study on Adhesive Intestinal Obstruction in a Tertiary Care Centre, South India. Int J Intg M ed Sci 2015;2(10):178-181. DOI: 10.16965/ijims.2015.133 